\title{
Análise do Software
}

\author{
A Terra em Transformação: Ciências Físicas e Naturais
}

CLÁUdA SUSANA NUNES SIMÕES ${ }^{1}$, JOÃO PAULO LEAL ${ }^{2}$

\section{Introdução}

A informática faz parte das nossas vidas e os programas informáticos são hoje auxiliares preciosos, constituindo ofertas habituais com que obsequiamos em especial os mais novos. Muitos dos programas que oferecemos são tidos como pedagógicos e auxiliares da aprendizagem e por isso mesmo se torna imperioso que se verifique se assim é.

O programa em análise é um programa de Ciências (Físico-Químicas e Naturais) comercializado pela Texto Editora e destina-se a alunos do $3 .^{\circ}$ ciclo do ensino básico. Basicamente é um programa tutorial de Ciências, contendo também exercícios e testes sobre os vários conteúdos abordados. A análise aqui apresentada refere-se à secção de Ciências Físico-Químicas.

\section{Meios necessários}

Os requisitos mínimos anunciados para este programa são o sistema operativo Windows 98, 2000, Me ou XP; processador $233 \mathrm{MHz}$; memória de $64 \mathrm{MB}$; placa de som; CD-ROM 16x; placa gráfica de $4 \mathrm{MB}$ e resolução de $800 \times 600$ e $50 M B$ de espaço livre no disco rígido. Para a análise do mesmo foi utilizada uma máquina com as seguintes características: Windows 98, processador Athlon de $900 \mathrm{MHz}$; memória de $128 \mathrm{MB}$; placa de som; DVD-ROM, 40x em leitura de CD-ROM; placa gráfica de 64 MB.

\section{Descriçẽo do programa e sua avaliação}

Certos alunos para aprender utilizam preferencialmente as suas capacidades auditivas, outros as visuais, outros as de leitura e outros ainda ao aprenderem utilizam as três capacidades. Este programa, ao permitir que o aluno ouça, leia e veja, promove todas essas capacidades. Apresenta, no entanto, uma deficiente qualidade sonora e a informação que transmite é em alguns casos demasiadamente simplificada mesmo para o nivel a que se destina.

0 écran inicial (figura 1) não apresenta a hipótese de escolher um perfil de uti- lizador. Cada vez que se utiliza o programa, têm de se preencher os campos "nome" e "data de nascimento".

No segundo écran podemos constatar que o programa apresenta a opção entre Ciências Naturais e Ciências Físico-Químicas. Isto está de acordo com a reorganização curricular do $3 .^{\circ}$ ciclo do ensino básico, que contempla uma nova área disciplinar "Ciências Físicas e Naturais", que se desdobra em Ciências Naturais e Ciências Físico-Químicas, que são leccionadas em paralelo.

Selecionando Ciências Físico-Químicas acede-se ao écran principal dessa opção (figura 2). onde não é claro onde

figura 1 Écran inicial

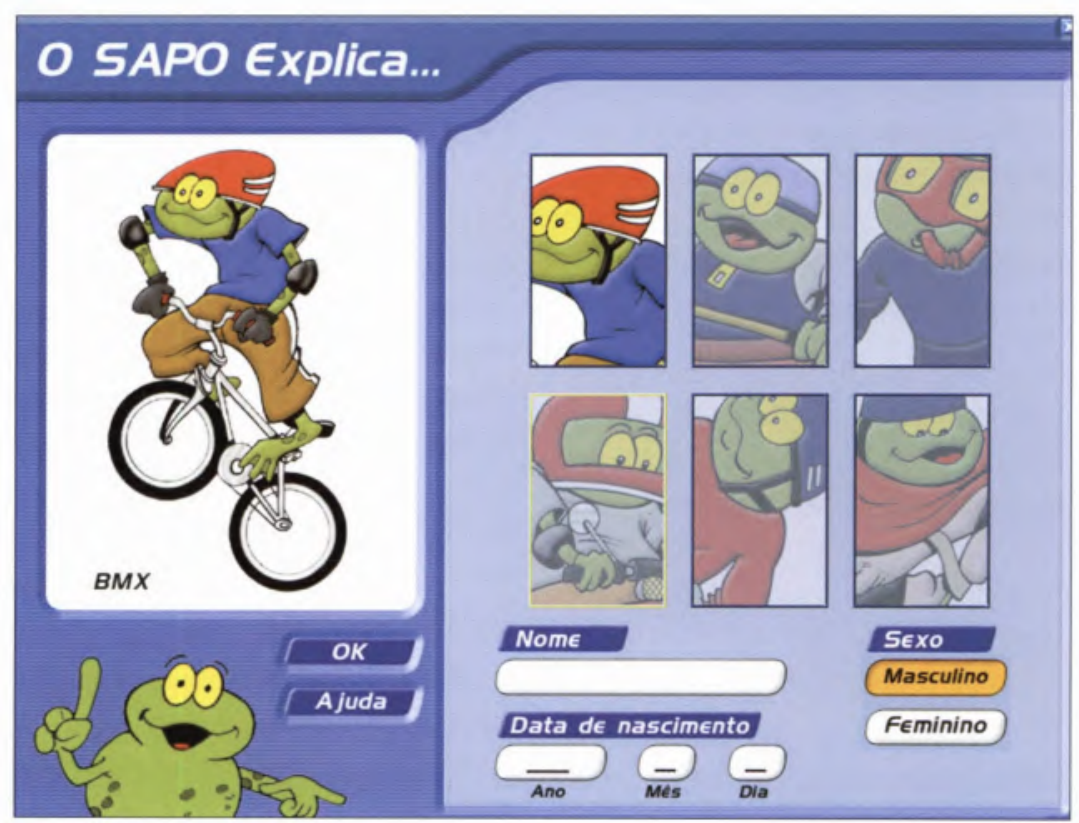

${ }^{1}$ Escola Básica 2, 3 Dom António da Costa - Almada.

${ }^{2}$ Departamento de Química, Instituto Tecnológico e Nuclear

Departamento de Química e Bioquímica e Centro de Química e Bioquímica, Faculdade de Ciências, Universidade de Lisboa 


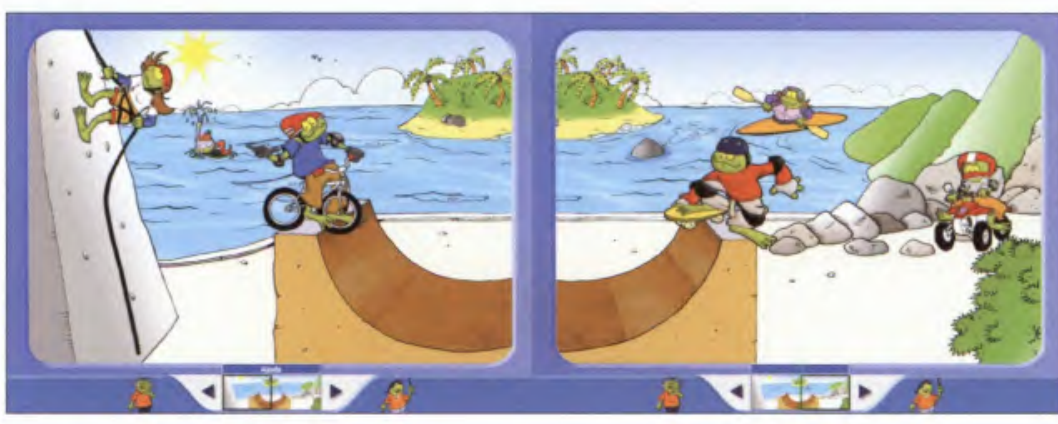

figura 2 Écran principal da opção Ciências Físico-Químicas

se deve clicar para ter acesso às diferentes funçōes do programa. Apenas as bandeiras amarelas que aparecem quando se passa por cima de cada um dos bonecos esclarecem o utilizador.

No fundo de todos os écrans existem botōes gerais, que se destinam a seleccionar directamente cada um dos écrans, sem necessitar de recorrer ao écran inicial (figura 3). Os vários botões são, no entanto, pouco intuitivos, não sendo imediato o reconhecimento das suas funções. Mesmo ao passar com o
Químicas o aluno tem à sua escolha dois temas: "Fontes e formas de energia" e "Materiais", cada um com os respectivos subtemas (figura 4). Ambos os temas estão de acordo com o novo programa oficial do $3 .^{\circ}$ ciclo do ensino básico. Deveriam no entanto, ter colocado o tema "Materiais" antes do tema "Fontes e formas de energia" uma vez que é essa a ordem pela qual os dois temas sầo leccionados.

Relativamente à explicação sonora de cada lição, a qualidade do som é fran-

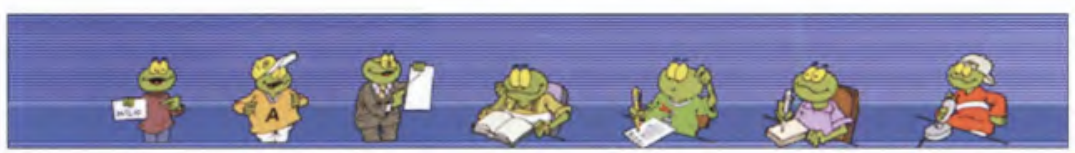

figura 3 Botões gerais existentes em todos os écrans.

cursor pelos botões não é fácil ver a sua função uma vez que a etiqueta identificativa nem sempre aparece com a facilidade desejada. Em contrapartida a sua função está bem descrita no écran de ajuda correspondente.

Todos os écrans de ajuda estão de um modo geral bem concebidos. As únicas falhas encontradas são a inexistência de indicação de como voltar ao écran principal e o facto de os écrans de ajuda referentes à "Sala de aulas", "Sala de estudo" e "Sala de testes" não corresponderem ao programa de Ciências Físico Naturais mas sim ao de Língua Portuguesa.

Na secção "Sala de aulas" é dada, ao aluno, a hipótese de escolha entre Ciências Físico-Químicas e Ciências Naturais. Relativamente a Ciências Físico- cios, o que dá ao aluno a possibilidade de realizar exercícios à medida que aprende com as lições. No entanto, os exercícios apresentados são referentes ao subtema a que pertence a lição e não especificamente à lição.

A partir das várias lições é possivel aceder ao glossário e aos utilitários, o que valoriza bastante as lições. Estas opções deveriam estar também acessíveis a partir do écran principal.

O glossário apresenta conceitos de Ciências Físico-Químicas e de Ciências Naturais, referentes não só a temas tratados neste programa mas também a outros temas que os alunos a esta altura já estudaram ou irão brevemente estudar.

Relativamente aos utilitários, o conversor de medidas apresenta um erro: onde está "Peso" deveria estar "Massa". O cálculo de potências está muito bem explicado, apresenta uma explicação sonora que está de acordo com o que é visivel no écran mas o som continua, também aqui, a ser de má qualidade. $\mathrm{A}$ imagem das divisões por época, perde um pouco do seu interesse por não estar toda visível no écran.

O écran "Sala de estudo" é, na apresentação de temas e subtemas, semelhante ao écran "Sala de aulas". Ao escolher um subtema passamos aos exercícios correspondentes (figura 6).

A presença do glossário, dos utilitários e das ligações para a lição correspondente à questão colocada e também a explicação do sapo valorizam bastante as páginas de exercícios uma vez que podem servir de auxílio ao aluno.

No entanto, são apresentados poucos exercícios sobre cada subtema e em entradas posteriores na "Sala de estudo" os exercícios continuam os mesmos. Alguns dos exercícios apresentados são semelhantes a exercícios presentes em manuais de Ciências Físico-Químicas do $7 .^{\circ}$ ano de escolaridade desta editora; outros, possuem vários tipos de faIhas. Algumas destas falhas ocorrem ao nível do enunciado podendo ser erros ortográficos, falta de figuras, opções de resposta incompletas, ambas correctas
A partir de cada lição é apresentado uma ligação para a página de exercí-
A indicação do tema, subtema e lição em estudo, bem como a selecção de outro tema, subtema ou lição estão facilmente acessíveis, pelos ícones na parte superior da página. 
ou inadequadas ou então legendas de figuras incorrectas. Outras falhas ocorrem ao nível das explicações/lições apresentadas para auxílio que são pouco ou nada conclusivas, alguns exercício chegam mesmo a apresentar erros de índole científica. Estas falhas encontram-se enumeradas na Tabela 1. Como exemplo pode observar-se a figura 6. Neste exercício o enunciado apresenta erros ortográficos, falta de opções de resposta para F, G e H e as opções de resposta que são fornecidas não permitem responder a $\mathrm{B}$ e $\mathrm{E}$. Se se consultar a explicação deste exercício ela não é conclusiva.

A "Sala de teste" só permite realizar testes sobre um dos dois temas e não sobre um dos vários subtemas. Ao es-

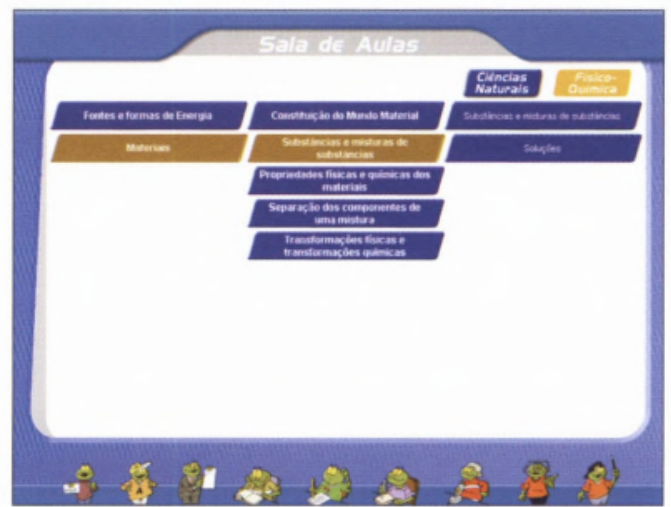

figura 4. Écran de "Sala de aulas"

colher um tema da sala de testes passamos a um dos vários écrans de testes (figura 7). Cada um deles é constituído por 10 questões. A única falha foi terem concebido os testes com as mesmas questões dos exercícios da "Sala de es- tudo". Cada teste constitui, assim, unicamente uma diferente combinação dos ditos exercícios, que possuem as falhas atrás descritas.

O écran "cartão sapo" permite saber quantos são os pontos obtidos, mas

Tabela 1: Falhas encontradas nos exercícios propostos para cada subtema

\begin{tabular}{|c|c|c|c|c|c|c|}
\hline \multirow[t]{2}{*}{ Tema } & \multirow[t]{2}{*}{ Subtema } & \multirow[t]{2}{*}{ Questão } & \multicolumn{4}{|c|}{ Tipos de falhas } \\
\hline & & & Enunciado & Falta de figuras & Explicações & Erros científicos \\
\hline
\end{tabular}

Materiais

Substâncias e

mistura de substâncias

Propriedades físicas

e químicas dos materiais

Separação dos componentes

de uma mistura

Transformações

físicas e químicas

\section{6}

7

8

9

1

5

1 $\otimes$

$\otimes$

$\otimes$

$\otimes$

$\otimes$

$\otimes$

$\otimes$

$\otimes$

$\otimes$

Fontes e

formas

de energia

\begin{tabular}{|c|c|c|}
\hline Formas de energia & 2 & $\otimes$ \\
\hline \multirow[t]{2}{*}{ Unidades de energia } & 4 & $\otimes$ \\
\hline & 5 & $\otimes$ \\
\hline \multirow{4}{*}{$\begin{array}{l}\text { Energia transferida } \\
\text { entre sistemas }\end{array}$} & 1 & $\otimes$ \\
\hline & 4 & \\
\hline & 5 & \\
\hline & 6 & \\
\hline \multirow{2}{*}{$\begin{array}{l}\text { Mecanismos de transferência } \\
\text { de energia como calor }\end{array}$} & 1 & \\
\hline & 3 & $\otimes$ \\
\hline Energia transferida & 1 & \\
\hline como trabalho & 2 & $\otimes$ \\
\hline
\end{tabular}


figura 5. Écran exemplificativo de uma lição

figura 6. Exemplo de um exercício

figura 7. Exemplo do exercício de um teste

figura 8. Écran de acesso ao jogos
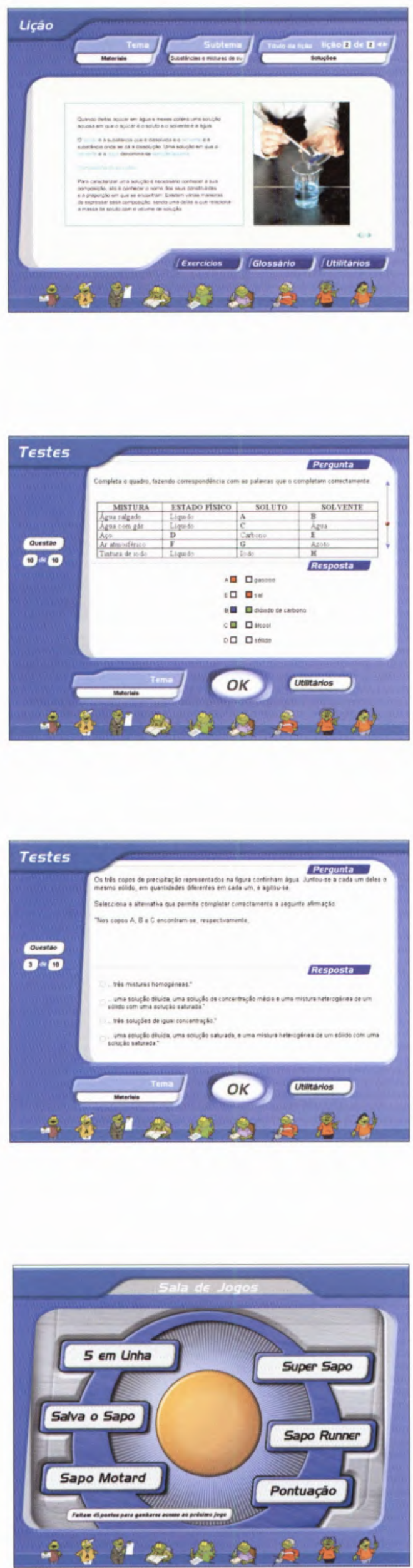

neste écran não está explicado como se podem obter pontos, nem para que servem. No écran "Sala de jogos" voltamos a ter uma referência a pontuação e novamente não temos as explicações atrás citadas (figura 8). Para se terem esses esclarecimentos tem de se consultar a Ajuda, que indica que os pontos obtidos correspondem a respostas correctas nos exercícios e testes. Por cada conjunto de respostas correctas obtêm-se 5 pontos, que são necessários para aceder a mais jogos (inicialmente só está disponivel o jogo 5 em linha). No início dos vários jogos também não existe uma explicação, só existindo na opção de ajuda.

\section{Melhorias a introduzir}

Para melhorar o programa deveriam ser tomados em conta os pontos negativos atrás descritos. Nomeadamente, relativamente à interface, que é na maioria das situações pouco clara e pouco intuitiva, uma possível melhoria seria no écran inicial existir uma opção de perfil de utilizador e serem criados botões gerais mais intuitivos. Os écrans de ajuda deviam referir-se a temas e subtemas de Ciências Físico-Químicas. 0 som do programa, deveria ser melhorado e deveriam ser dadas explicações concordantes com o texto e as figuras fornecidas. Seria interessante a presença de pequenos filmes exemplificativos de certos conteúdos. Os exercícios e as ligações para os apoios deveriam ser revistos introduzindo também maior variedade de exercícios e testes. Estes últimos deveriam conter questões diferentes das presentes nos exercícios. Os jogos apresentados deveriam estar relacionados com as Ciências Físico-Químicas de modo a permitirem uma continuação da aprendizagem, mesmo durante o jogo.

Uma vez que se trata de um programa de nível introdutório às Ciências FísicoQuímicas seria útil a existência de uma página com material de laboratório e regras básicas de segurança. Seria também conveniente a sugestão de actividades para o aluno. 


\section{Comentário final}

O programa de Ciências Físicas e Naturais nos três ciclos do ensino básico está organizado em quatro grandes temas gerais: "Terra no Espaço", "Terra em transformação", "Sustentabilidade na Terra" e "Viver melhor na Terra". Com o tema "Terra em transformação" pretende-se que os alunos adquiram conhecimentos relacionados com os elementos constituintes da Terra e com os fenómenos que nela ocorrem. Os vários temas devem ser explorados numa perspectiva interdisciplinar. Estes pontos não estão muito explícitos neste software.

Como referido este programa destina-se a alunos do $3 .^{\circ}$ ciclo do ensino básico, essencialmente a alunos do $7 .^{\circ}$ ano de escolaridade. Estes alunos contactam pela primeira vez com a disciplina de Ciências Físico-Químicas. 0 modo simples como o tema é abordado é adequado ao nível inicial dos alunos. No entanto, certos conteúdos poderiam ser um pouco mais aprofundados e pode- riam ser sugeridas actividades para o aluno realizar promovendo a pesquisa de informação, a resolução de problemas, a tomada de decisões e gerando curiosidade para a ciência.

Deveria existir uma página de apresentação do programa em que fosse explicado qual o seu objectivo, as suas opções e os seus conteúdos. Para quem utiliza o programa pela primeira vez, não é, por exemplo, clara a diferença entre as salas de aulas, de estudo e de testes. O programa não possui manual. No verso da capa da caixa do CD-ROM existe unicamente a descrição do procedimento de instalação.

A ideia de fazer testes foi bem pensada, mas como as questões são as mesmas que existem nos exercícios o aluno não está realmente a testar os seus conhecimentos, está só a refazer exercícios. Poderiam ter realizado os testes com algumas questões semelhantes (não iguais) às dos exercícios mas outras teriam obrigatoriamente de ser diferentes, caso contrário está-se a apelar à memorização de exercícios e não á sua compreensão e aplicação a novas situações.

O modo como a opção de jogos foi colocada parece positiva pois, a vontade de atingir novos níveis de jogos pode, para os alunos deste nível etário, funcionar como estímulo à correcta realização dos exercícios e dos testes.

Apesar dos muitos erros encontrados, e que podem limitar a utilização autónoma do programa por parte dos alunos, ele tem a vantagem de não ter concorrência pois não existem programas similares, em língua portuguesa, no mercado. Sem deixar de pôr em relevo a coragem da Texto Editora em se lançar nesta aventura de produzir Software Educacional em português, o programa em causa não recolhe ainda uma classificação positiva. Espera-se que em breve possam aparecer mais e melhores programas nesta área.

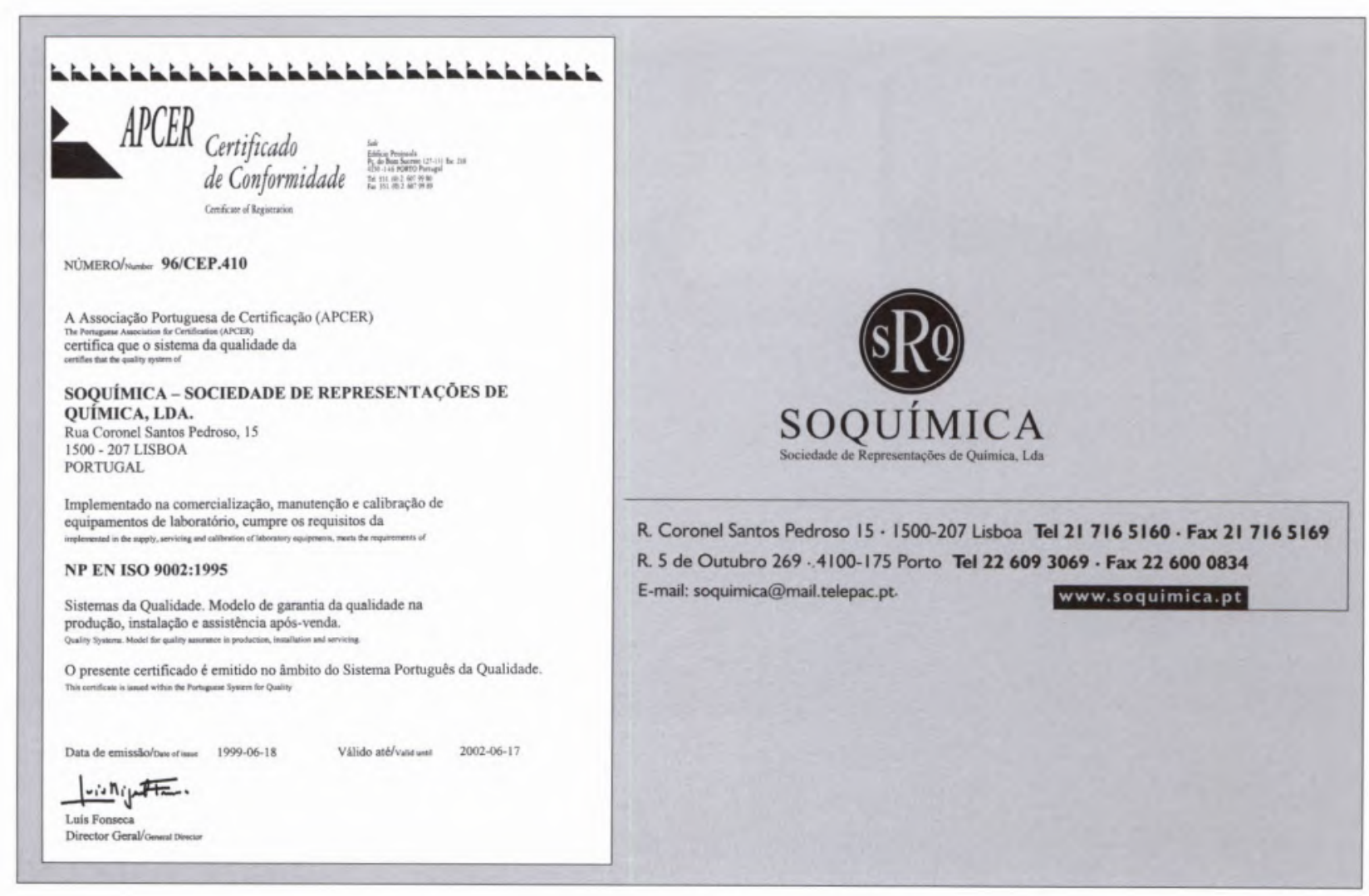

